\title{
sistêmica pós-colonial das diferenças \\ no interior da sociedade mundial moderna
}

Roberto Dutra*

Resumo: As aproximações entre os pressupostos epistemológicos e ontológicos da teoria social de Niklas Luhmann e das abordagens pós-coloniais têm sido ressaltadas e desenvolvidas na última década. No âmbito das teorias pós-coloniais, o ponto de vista pós-fundacionalista leva à desconstrução dos discursos hegemônicos e eurocêntricos sobre a modernidade, operando uma observação crítica das operações cognitivas e práticas que constroem, num registro essencialista, identidades e casos nacionais baseados nas autocompreensões (neo)colonialistas dos países ditos centrais ou desenvolvidos. Na medida em que a teoria social de Niklas Luhmann parte de pressupostos ontológicos e epistemológicos muito semelhantes, poder-se-ia esperar uma abordagem desconstrutivista também em sua teoria da sociedade moderna, mas, até agora, prevalece quase unânime a percepção de que a concepção luhmanniana de sociedade mundial é incorrigivelmente eurocêntrica. Pode sua teoria da sociedade mundial não ser eurocêntrica? Apoiando-se em debates mais recentes e menos ortodoxos sobre esta teoria, defende-se nesta comunicação a tese de que a teoria da sociedade mundial de Luhmann pode ser recepcionada em favor da crítica ao discurso hegemônico e eurocêntrico sobre a modernidade.

Palavras-chave: Modernidade. Colonialidade. Sociedade mundial. Teoria dos sistemas. Pós-colonialismo.

\section{For a post-colonial systemic sociology of the differences within the modern world society}

Abstract: The approximations between the epistemological and ontological assumptions of Niklas Luhmann's social theory and postcolonial approaches have been emphasized and developed in the last decade. In the context of postcolonial theories, the post-foundationalist point of view leads to the deconstruction of hegemonic and eurocentric discourses on modernity, operating a critical observation of cognitive and practical operations that build, in an essentialist register, national identities and cases based on self-(neo)colonialist understandings of the so-called central or developed countries. To the extent that Niklas Luhmann's social theory starts from very similar ontological and epistemological assumptions, one might expect a deconstructive approach also in his theory of modern society, but until now prevails almost unanimously the perception that the Luhmannian conception of world society is incorrigibly eurocentric. Can this theory of world society not be eurocentric? Relying on more recent and less orthodox debates on this theory, it is argued in this communication that Luhmann's theory of world society can be adopted in favor of criticism of the hegemonic and eurocentric discourse on modernity.

Keywords: Modernity. Coloniality. World Society. Theory of systems. Postcolonialism.

\author{
* Roberto Dutra é \\ doutor em sociologia \\ pela Humboldt \\ Universität zu \\ Berlin, mestre em \\ Políticas Sociais \\ pela Universidade \\ Estadual do Norte \\ Fluminense Darcy \\ Ribeiro (UENF). \\ Atualmente é \\ Professor Associado \\ do Laboratório de \\ Gestão e Políticas \\ Públicas (LGPP) da \\ UENF, Rio de Janeiro, \\ Brasil. \\ Orcid: 0000-0001- \\ 7854-1139. \\ $<$ robertodtj@gmail. \\ com>.
}




\section{Introdução}

s aproximações entre os pressupostos epistemológicos e ontológicos da
teoria social de Niklas Luhmann e as abordagens pós-coloniais têm sido
ressaltadas e desenvolvidas na última década. Os esforços de aproximação
focam, dentre outros aspectos, o ponto de vista pós-fundacionalista, que consiste
em recusar a ontologia das identidades, das essências, das substâncias e dos fun-
damentos últimos em favor de uma perspectiva da diferença a privilegiar as opera-
ções cognitivas e práticas de diferenciação como as responsáveis pela construção
da realidade social (Gonçalves, 2013).

No âmbito das teorias pós-coloniais, o ponto de vista pós-fundacionalista leva à desconstrução dos discursos hegemônicos e eurocêntricos sobre a modernidade, operando uma observação crítica das operações cognitivas e práticas que constroem, num registro essencialista, identidades e casos nacionais baseados nas autocompreensões colonialistas dos países ditos centrais ou desenvolvidos. Nessas teorias, o discurso da modernidade ocidental sobre si mesma (e sobre o seu "outro" - o "Oriente", a "América Latina", o "resto") é, portanto, o principal objeto de desconstrução, tendo como estímulo histórico-empírico as experiências das regiões pós-coloniais - América Latina, Ásia e África - com a modernidade (Miglievich-Ribeiro, 2014; Mignolo, 2002; Quijano, 1997).

Na medida em que a teoria social de Luhmann parte de pressupostos ontológicos e epistemológicos muito semelhantes, poder-se-ia esperar uma abordagem desconstrutivista também em sua teoria da sociedade moderna, mas, até agora, prevalece quase unânime a percepção de que a concepção luhmanniana de sociedade mundial é incorrigivelmente eurocêntrica (Souza, 2011). Isso significa que a teoria da sociedade de Luhmann não poderia ser lida e desenvolvida em função do objetivo estratégico de construir uma "sociologia pós-colonial" (Boatcă \& Costa, 2010). Por exemplo, esforços de construir uma sociologia da modernidade na América Latina a partir da teoria da sociedade mundial funcionalmente diferenciada de Luhmann - como se tem constatado no caso de Marcelo Neves - estariam condenados a replicar ou atualizar a lógica cognitiva (colonial) de perceber a "modernidade periférica" como "negativa" e deficitária em termos do acesso aos princípios estruturais da modernidade (Souza, 2011).

A crítica pós-colonial apontaria - com toda razão - que as diferenças "modernidade positiva" × "modernidade negativa", assim como os déficits de diferenciação funcional atribuídos "ontologicamente" e exclusivamente a determinadas regiões 
(Dutra, 2016a), constituem uma versão renovada da diferença política pós-colonial, que reifica padrões regionais de sociabilidade como métrica para práticas e discursos de comparação que inferiorizam e tornam periféricos, em diversas dimensões e esferas, outros padrões não convergentes de forma igualmente ontológica e exclusiva.

Esta percepção é justa em face do potencial e da complexidade da teoria de Luhmann? Pode sua teoria da sociedade mundial não ser eurocêntrica? Podemos recepcioná-la de um modo em que as diferenças e desigualdades regionais não sejam subsumidas em categoriais reificadas e reificadoras como moderno $\times$ atrasado, positivo $\times$ negativo, plenitude $\times$ déficit?

Ao se apoiar em debates mais recentes e menos ortodoxos sobre esta teoria, este texto defende a tese de que a teoria da sociedade mundial de Luhmann pode ser recepcionada em favor da crítica ao discurso hegemônico e eurocêntrico sobre a modernidade. E isto sem violar nenhum de seus pressupostos e conceitos fundamentais. O argumento principal é que as análises de Luhmann sobre os efeitos e paradoxos da diferenciação da sociedade em subsistemas já haviam rompido com o discurso hegemônico sobre a modernidade. E, apesar dos elementos inegavelmente eurocêntricos, é possível defender o primado da "face pós-colonial" na teoria dos sistemas, sem, no entanto, recorrer à extrapolação da categoria do "político" e das narrativas de dominação e poder para descrever a variedade global de padrões de sociabilidade moderna e, ao mesmo tempo, sendo capaz de romper com naturalizações das diferenças coloniais à medida que desenvolve sensibilidade teórica e empírica para a dimensão cognitiva da colonialidade que perpassa a ciência e a filosofia sociais modernas.

Sustento que a teoria de Luhmann pode servir de base para uma "sociologia pós-colonial" (Boatcă \& Costa, 2010) capaz de combinar a análise da unidade da sociedade mundial com a consideração das diferenças e variedades construídas em seu interior. No entanto, a teoria da sociedade de Luhmann tem um problema grave que precisa ser enfrentado, e para o qual tem demonstrado pouca sensibilidade: sua descrição da transição à sociedade moderna enxerga somente um processo de diferenciação singular e interno à Europa, desconsiderando, como Walter Mignolo (2002) diria, o papel da "diferença colonial" na constituição da chamada "transição para a modernidade". Para se constituir como "sociologia pós-colonial" capaz de compreender a globalidade das diferenças regionais, a teoria dos sistemas precisa não apenas investir em estudos sobre a globalização dos sistemas funcionais a partir do século XIX (Werron, 2007), tendo a Europa como núcleo difusor dos proces- 
sos sociais globais, mas, sobretudo, questionar e revisar sua descrição da própria transição para a sociedade moderna, realizando uma profunda autocrítica. Seria preciso, portanto, problematizar a tese da transição para a sociedade mundial funcionalmente diferenciada, a fim de escapar da narrativa da singularidade ocidental (Chakrabarty, 2000: 7), segundo a qual as demais regiões recebem, sempre de fora para dentro, estruturas sociais e semânticas gestadas primeiramente na Europa.

O maior desafio para a teoria da sociedade mundial é o de recontar a história da modernidade, substituindo a narrativa única de uma diferenciação funcional desenvolvida inicialmente no interior da Europa e depois expandida para o resto do mundo por narrativas plurais sobre a experiência de cada contexto "geo-histórico" como parte do desenvolvimento "entrelaçado" (Randeria, 2000) e "múltiplo" (Eisenstadt, 2000) de sistemas funcionais globais (Grizelj \& Kirschstein, 2014: 12). É preciso, também na teoria dos sistemas, problematizar a história do Ocidente e partir das relações e diferenças que o constituíram, sem necessariamente negar a centralidade da Europa e dos Estados Unidos no processo de surgimento da modernidade, mas sim de observá-la a partir da própria diferença centro $\times$ periferia, o que se configura - a meu ver - como resultado de um diálogo crítico e produtivo entre a teoria dos sistemas e o pós-colonialismo. Como ressalta José Maurício Domingues (2008: 125-126), não é necessário negar a - inegável - centralidade da Europa na formação inicial da modernidade para ressaltar o papel constitutivo que os contatos e entrelaçamentos com as demais regiões do planeta tiveram neste processo.

A grande diversidade de teorias pós-coloniais dificulta uma discussão com validade mais abrangente sobre suas semelhanças e diferenças com a teoria dos sistemas de Luhmann. No entanto, pretendo restringir meu diálogo com a abordagem do semiólogo argentino Walter Mignolo, a qual incorpora a tradição latino-americana de teorias e pesquisas sobre a dependência e as relações múltiplas entre centro e periferia para construir sua análise sobre o esquecimento da "diferença colonial" na filosofia e nas teorias sociais e políticas modernas. Diferentemente da grande maioria das ciências sociais e da filosofia (que também se estende a Luhmann), que localizam a transição para a modernidade na virada do século XVIII para o século $X I X$, esquecendo os três séculos anteriores de relações coloniais constitutivas para a formação das identidades "geo-históricas" na Europa, as teorias sobre a dependência e as relações centro-periferia, cuja síntese teórica Mignolo localiza na obra de Immanuel Wallerstein,

põem o colonialismo em tela, ainda que apenas como um elemento derivado, e não constitutivo, da modernidade, pois ainda não 
tornam visível a colonialidade, o outro (escuro?) lado da modernidade (Mignolo, 2002: 60).

O artigo está dividido em quatro seções. Na primeira, recapitulamos as proximidades epistemológicas e ontológicas entre a teoria dos sistemas e os "pós-colonialismos" encontradas na literatura recente. Na segunda parte, comparamos as semelhanças e as diferenças entre as duas abordagens em relação ao modo como interpretam as diferenças sociais produzidas no interior da sociedade mundial, dialogando especificamente com o semiólogo Mignolo. Na terceira seção, analisamos mais detidamente o problema da autologia na crítica pós-colonial, ou seja, o problema "iluminista sociológico" de refletir sobre as condições - e os limites - sociais de possibilidade da crítica social. Neste ponto, a teoria dos sistemas de Luhmann pode nos ajudar a corrigir o déficit de reflexividade autológica da crítica pós-colonial, identificando na superação, pelo sistema da sociedade, do caráter necessário e primário da "diferença colonial" o eixo teórico central nesta tarefa de correção. Na quarta e última parte, esboçamos os traços básicos de uma teoria sistêmica da sociedade mundial submetida a um processo de descolonização, indicando o que precisa ser corrigido na teoria da sociedade mundial de Luhmann para que ela não fique cega à "diferença colonial" e assim seja capaz de inspirar uma "sociologia pós-colonial".

\section{Teoria dos sistemas e as abordagens pós-coloniais}

Na última década, alguns trabalhos (Gonçalves, 2013; Grizelj \& Kirschstein, 2014; Eckstein \& Reinfandt, 2014) ressaltaram as afinidades entre a teoria luhmanniana dos sistemas e as teorias pós-coloniais e decoloniais. Em termos gerais, estes esforços destacam as enormes semelhanças epistemológicas e ontológicas entre as duas abordagens, especialmente o ponto de partida de uma teoria da diferença (em oposição às teorias das identidades, das essências e dos fundamentos), a desconstrução da distinção ontológica entre sujeito e objeto e a ruptura com a ideia de um conhecimento neutro e desengajado de seus objetos, em favor de uma teoria do conhecimento em que o conhecer é uma das operações fundamentais (da autoconstituição) dos próprios objetos estudados.

i. Teoria da diferença. Em que pese a grande diversidade no interior do que se convencionou chamar de teorias pós-coloniais ou decoloniais, todas elas comungam com a teoria dos sistemas de Luhmann a premissa de que as realidades constituídas por sentido (social e psíquico) são, não apenas na última, mas em todas as instâncias, diferenças en- 
tre o sentido selecionado e o sentido não selecionado, mas reproduzido como possibilidade, como virtualidade em face da qual o sentido selecionado torna-se contingente. Ao invés de partir da existência de determinadas identidades, estruturas e referências fixas, o postulado é que toda identidade, estrutura e referência é constituída por operações de sentido que traçam distinções: o "Ocidente" precisa distinguir-se do "Oriente" (Eduard Said) ou do "resto do mundo" (Stuart Hall) para formar e reproduzir sua identidade de "Ocidente"; o sistema precisa distinguir-se do ambiente para formar e reproduzir sua identidade de sistema (Gonçalves, 2013; Eckstein \& Reinfandt, 2014).

ii. Desconstrução da distinção ontológica entre sujeito e objeto. Outra grande semelhança entre as duas abordagens aqui tratadas é a crítica à filosofia/ontologia do sujeito que concebe este último como instância cognitiva ontologicamente separada do mundo, seja na esfera do conhecimento seja na da ação prática. O cogito cartesiano perde - tanto para os pós e decoloniais como para Luhmann e os luhmannianos - a condição de instância privilegiada do conhecimento e da ação, tornando-se uma construção histórica, contingente e precária das operações e dos discursos que também são responsáveis pela constituição dos objetos do conhecimento. O que se designa como sujeito e o que se designa como objeto são constituídos pelas mesmas operações de sentido que produzem o conhecimento enquanto saber situado no mundo, sobre o mundo e para o mundo. Ou - como diria Luhmann -, observador e observado resultam da mesma base operativa (Luhmann, 1997: 875).

iii. Ruptura com a ideia de um conhecimento neutro e desengajado. A terceira importante afinidade epistemológica e ontológica entre teoria dos sistemas e teorias pós e decoloniais é a própria concepção de conhecimento que resulta das outras demais premissas. Para ambas, o conhecimento é sempre conhecimento engajado, ou seja, criado e reproduzido a partir de problemas reais como o desafio do colonizador em estabilizar a "diferença colonial" (colonizador x colonizado) por meio de conceitos e semânticas que fixem ontologicamente a relação de superioridade $\times$ inferioridade moral entre os dois lados da diferença e legitimem sua reprodução, ou o desafio dos sistemas sociais em conhecer os efeitos do ambiente instável sobre a continuidade das operações sistêmicas. Mesmo que a modernidade científica seja descrita por Luhmann como constituída por um sistema funcional autopoiético fundado em operações que codificam e validam o co- 
nhecimento como - cientificamente - verdadeiro ou falso, a produção e circulação de conhecimento científico, ainda que subordinadas ao imperativo de uma diferença binária funcionalmente especializada (o código verdadeiro $\times$ falso), é concretamente programada e organizada por influência de acoplamentos estruturais da ciência com os demais sistemas funcionais como economia e política, ou seja, é sempre ciência influenciada, embora não determinada na complexidade interna de duas operações, pelo seu acoplamento - "engajamento" - com as operações do ambiente societal (Neves, 2009; 2014). Na medida em que ciência é sempre ciência acoplada e organizada, ela é sempre condicionada por fatores extracientíficos locais, como interesses políticos (coloniais, anticoloniais, desenvolvimentistas), econômicos etc.

Aqui é importante fazer duas ressalvas.

i. Essas afinidades epistemológicas e ontológicas não ficam restritas às duas vertentes teóricas; elas se estendem também às abordagens pós-estruturalistas e pós-fundacionistas (Garcia da Costa \& Rodrigues, 2017) de autores como Ernesto Laclau, Chantal Mouffe e Judith Butler. Essas abordagens também recusam sistematicamente a ontologia das identidades, das essências, das substâncias, das "estruturas necessárias e profundas" (Unger, 2004) e dos fundamentos últimos em favor de uma perspectiva da diferença que privilegia as operações cognitivas e práticas de diferenciação como as responsáveis pela construção da realidade social e de "fundamentos contingentes" (Butler, 1992).

ii. É preciso ressaltar que essa crítica epistemológica e ontológica que aproxima teoria dos sistemas, pós-colonialismo, pós-estruturalismo e pós-fundacionismo não é exclusividade, pelo menos em suas principais características na prática do produzir e fazer circular a ciência social, das vertentes teóricas cujo vigor é contemporâneo ao fim da Guerra Fria e ao desafio de criticar os discursos científicos hegemônicos que emulam a impossibilidade de alternativas aos padrões de sociabilidade do Atlântico Norte.

As teorias pós-coloniais e decoloniais contemporâneas, apesar de diferenças de orientação teórico-filosóficas, apresentam uma concepção comum sobre o social em grande medida distinta da teoria luhmanniana dos sistemas sociais. Embora compartilhem com Luhmann o ponto de partida de uma teoria da diferença, as teorias pós-coloniais e decoloniais, assim como as teorias "pós-estruturalistas" do 
poder (Holmes, 2013), tendem a subsumir todas as diferenças sociais à dimensão política: "as diferenças são sempre formas de assimetria de poder entre povos" (Gonçalves, 2013: 263). Ao invés de definir as diferenças políticas (superioridade de poder $x$ inferioridade de poder) como esfera específica de relações sociais, fundada na diferenciação do poder como meio simbolicamente generalizado de comunicação, as teorias pós-coloniais e decoloniais alargam ao máximo a concepção do "político", partindo da premissa de que todas as diferenças encontradas na sociedade são, no fundo, diferenças de poder ou dela resultantes. Enquanto em Luhmann, a política seria uma das formas contingentes assumidas pelo social precisamente enquanto forma funcionalmente diferenciada de comunicação -, ao lado de outras formas do social como a economia, a religião etc., para as teorias pós-coloniais e decoloniais, o social é sempre político.

Este alargamento do político pode ser encontrado claramente no conceito de "colonialidade do poder" de Aníbal Quijano (1997), amplamente aceito e utilizado como categoria-chave no pensamento decolonial latino-americano (Mignolo, 2002). Mesmo sem reduzir todas as práticas e estruturas sociais do mundo social a este conceito, a "colonialidade" é concebida como padrão dominante de hierarquização, criado a partir do circuito comercial do Atlântico no século XVI, que produz suas próprias unidades dominadas e dominantes, seja em termos institucionais com o sistema colonial e neocolonial de Estados centrais e periféricos, seja em termos socioculturais com os processos de construção e universalização de etnias e raças enquanto critérios de classificação social hierarquizante de povos e posições na divisão do trabalho (Quijano \& Wallerstein, 1992). O conceito de "colonialidade do poder" surge para explicar por que o discurso e a prática de expandir a modernidade, a "civilização" e o "progresso" tendem a reproduzir relações hierárquicas, nas quais sujeitos, comunidades, e Estados-nações - juntamente com seus modos de ser, conhecer e agir - se localizam em uma área que está abaixo do humano. A colonialidade é precisamente o padrão hierarquizante que articula diversas modalidades de práticas e esferas sociais e que confere sentido geral, duradouro e definidor das relações entre um conjunto de estados e identidades étnico-raciais - "geo-históricas", diria Mignolo - no sistema-mundo que emerge com o circuito comercial e colonial do Atlântico:

[...] mesmo quando o status colonial formal chega a seu fim, não acaba a colonialidade. Ela persiste na forma de uma hierarquia sociocultural entre europeus e não europeus. É importante entender que todos os Estados neste sistema interestatal são criações novas - daqueles no topo àqueles na base da hierarquia (Quijano \& Wallerstein, 1992: 550). 
As hierarquias produzidas pela colonialidade correspondem ao padrão de dominação que subsistiria a todas as transições, até mesmo à transição para a diferenciação funcional, delimitada pelo fim do colonialismo político-administrativo e pela criação de Estados nacionais formalmente autônomos ${ }^{1}$.

Assim como os "direitos do homem" e a igualdade formal entre indivíduos - desde o jovem Marx - seriam meras ideologias para reproduzir e legitimar as desigualdades materiais entre as classes, o ideal igualitário entre povos e nações, embutido na independência formal de ex-colônias e institucionalizado pelo atual sistema da Organização das Nações Unidas (ONU), tal como a própria ideia de diferenciação funcional, não seriam também mais do que fenômenos ideológicos que emergem para justificar desigualdades regionais (Gonçalves, 2017). A diferenciação funcional estaria sempre subordinada ao padrão hierarquizante da colonialidade. Desta forma, enquanto esfera primária de produção das diferenças e desigualdades no interior do sistema-mundo moderno/neocolonial,

a hierarquia da colonialidade se manifesta em todos os domínios - político, econômico e, não menos importante, na esfera cultural. A hierarquia reproduz a si mesma no tempo, embora sempre tenha sido possível para poucos Estados modificar sua posição na hierarquia. Mas uma mudança na ordem das posições não perturba a existência contínua da hierarquia (Quijano \& Wallerstein, 1992: 550).

Na próxima seção, veremos como as semelhanças nas premissas epistemológicas e ontológicas e as diferenças na concepção sobre o social podem ser encontradas nas respectivas descrições que a teoria dos sistemas e a teoria de Mignolo fazem das diferenças encontradas na sociedade global.

\section{Teoria dos sistemas, pós-colonialismo e as diferenças no interior da sociedade mundial}

Podemos recepcionar a teoria de Luhmann sem que as experiências regionais com a modernidade sejam subsumidas em categoriais reificadas e reificadoras como moderno $\times$ atraso, positivo $\times$ negativo, plenitude $\times$ déficit? Ao se apoiar em debates mais recentes e menos ortodoxos sobre esta teoria, defende-se nesta comunicação a tese de que a teoria da sociedade mundial de Luhmann pode ser recepcionada em favor da crítica ao discurso hegemônico e eurocêntrico sobre a modernidade. As análises de Luhmann sobre os efeitos e paradoxos da diferenciação da sociedade em subsistemas já romperam, em grande medida, com o discurso hegemônico e

1. Coerente com o ponto de partida do primado da colonialidade na sociedade global, a diferenciação funcional como um todo e seus elementos normativos (igualdade formal) são reduzidos a mera "ideologia da sociedade neocolonial" (Gonçalves, 2017). 
teleológico sobre a modernidade, principalmente na última fase do autor. Nessas análises, problemas de "exclusão" e "corrupção sistêmica" não são relíquias do passado, mas produtos da expansão global dos sistemas funcionais, a qual não anula as particularidades de contextos e "histórias locais", mas condiciona e é também condicionada por estas particularidades, orientando-se pelas possibilidades e limitações de cada região.

No plano da teoria da sociedade, as abordagens "pós-coloniais" - assim como as decoloniais - e a teoria dos sistemas se preocupam com a produção de diferenças regionais. Embora as diferenças centro $\times$ periferia, trabalhada pela segunda, e a diferença Norte $\times$ Sul global, desenvolvida pelas primeiras, não sejam exatamente sinônimas, já que a diferença Norte $\times$ Sul global apresenta uma abrangência maior, as duas concepções destinam-se a um mesmo propósito: observar a construção de assimetrias regionais como produto da operação de diferenças a um nível suprarregional × global (Gonçalves, 2013: 250-251).

Porém, há neste ponto uma importante divergência no modo de conceituar essas diferenças globais: enquanto as teorias pós-coloniais definem a diferença primária como "diferença colonial" (Mignolo, 2002), entendida como relação de poder (colonialidade) que subordina conhecimento, autoridade política, economia, gênero, sexualidade etc. ao imperativo de dominação colonial ou neocolonial, já que toda diferença "é sempre condicionada, em contextos concretos, pela confrontação concreta com um 'outro'" (Eckstein \& Reinfandt, 2014: 120-121), a teoria dos sistema postula que a globalidade dos sistemas funcionais - portanto, a diferença funcional entre sistemas sociais globais - é o meio a partir do qual as diferenças regionais, que de resto nunca são anuladas pelo contato (colonial ou não) com a modernidade, são ressignificadas e reproduzidas, seja nos termos da diferenciação secundária centro $\times$ periferia, seja em termos mais simétricos.

Ao lado desta divergência importante, há, no entanto, uma convergência central entre as duas abordagens sobre a produção de diferenças regionais na sociedade contemporânea: a ruptura radical com a filosofia da história e com a concepção teleológica de evolução sociocultural. Como ressaltou Sérgio Costa, a crítica pós-colonial à visão teleológica da modernidade, fundada no esquecimento e na reprodução da "diferença colonial", na concepção de que as estruturas sociais dos países do Atlântico Norte constituem o telos, o "ponto de chegada", dos países do Atlântico Sul e na consequente negação de alternativas às formas de sociabilidade moderna contemporâneas, não se aplica ao conjunto da sociologia, mas apenas à "macrossociologia da modernização" (Costa, 2006: 129-130). Pois, no interior da própria sociologia, 
a crítica à teoria da modernização, escola de pensamento que vive sua fase áurea nos Estados Unidos, nos anos de 1950 e 1960, remonta pelo menos ao final da década de 1960, quando atacava-se, precisamente, o caráter etnocêntrico, endogenista de tal corrente e a suposição de que da "modernização" da economia decorreria, automaticamente, de transformações em outras esferas, como a democratização da política e a secularização cultural (Costa, 2006: 129-130).

A concepção, obtida por comparação assimétrica e idealizadora entre países e regiões, de um telos societal de integração entre as esferas sociais diferenciadas, que ignora as contradições e idealiza a integração e a harmonia entre elas, é o cerne de uma teoria da diferenciação funcional completamente cega à "diferença colonial" e às diferenças regionais como um todo, uma vez que percebe essas diferenças como elementos de "atraso" a serem superados pela evolução convergente dos sistemas sociais diferenciados. Se a teoria da sociedade mundial funcionalmente diferenciada de Luhmann partilhasse destas premissas, não seria possível nenhum diálogo com as teorias pós-coloniais e decoloniais. Teleologia e visão harmônica da diferenciação funcional se aplicam, por exemplo, a Parsons, mas não a Luhmann.

Na verdade, como a evolução da sociedade é aberta, pode haver tanto situações de equilíbrio entre diferentes sistemas funcionais como situações de domínio de um(uns) sobre outro(s) - como a colonização econômica das demais esferas demonstra. Colocada nestes termos - a meu ver -, a teoria da diferenciação funcional de Luhmann, assim como sua teoria da sociedade mundial, permitem romper com o quadro de referência da "perspectiva hegemônica da modernidade" (Tavolaro, 2014: 656), segundo o qual o equilíbrio entre os sistemas funcionais diferenciados e a inclusão universal seriam traços da modernidade central e desequilíbrio - assim como a "corrupção" - e exclusão características da modernidade periférica.

O projeto de Luhmann era desenvolver uma teoria da sociedade mundial contra o paradigma da teoria da modernização. Ele não parte de um modelo de diferenciação funcional no qual os sistemas funcionais coevoluem de forma harmoniosa, como se a autonomização da economia, da política, do direito, do ensino, da ciência etc. "fosse capaz de preencher funções de sustentação recíproca" (Luhmann, 1995a: 24). Ele parte, na verdade, da premissa oposta: "a elevada especialização e autonomização dos sistemas funcionais irá conduzir a prejuízos recíprocos" (Luhmann, 1995a: 25). Neste sentido, a relevância dos condicionamentos e das "histórias" locais para as estruturas dos sistemas funcionais não contradiz nem o caráter global destes sistemas, nem o primado global da diferenciação funcional como um todo. Na produção de variações locais engendradas por estes condicionamentos e estas 
histórias específicos de cada região, o primado da diferenciação funcional se mantém como referência supralocal de comparação intrassistêmica, uma vez que singularidades locais só podem existir em função de seus status comparados no interior dos sistemas funcionais globais.

Neste sentido, podemos afirmar que tanto a teoria dos sistemas como as teorias pós-coloniais valorizam epistemologicamente condicionamentos, estruturas e histórias regionais sem recorrerem ao paradigma do "nacionalismo metodológico", quase sempre implícito na sociologia com o conceito espontâneo de sociedade nacional. A teleologia e a filosofia da história estão vinculadas de modo umbilical ao "nacionalismo metodológico", pois a ideia de um telos convergente para o desenvolvimento social moderno, ou seja, de um ponto de chegada que atua como critério de comparação para definir estágios relativos de "atraso" e "modernidade" tem no imaginário sociológico das "sociedades nacionais" uma referência obrigatória.

O rompimento com a teleologia, presente de modo explícito na teoria dos sistemas e nos pós-colonialismos, exige o rompimento simultâneo com o "nacionalismo" metodológico", ou seja, com o privilégio epistemológico atribuído implícita ou explicitamente pelo discurso - sociológico - hegemônico sobre a modernidade às identidades "geo-históricas" dos países do Atlântico Norte: o privilégio de serem confundidas com a realização típica da modernidade, servindo de parâmetro para avaliar outras identidades "geo-históricas" como "atrasadas", desviantes, não modernas, subdesenvolvidas, em desenvolvimento, negativamente modernas, primitivas, bárbaras etc. Romper com este "privilégio epistemológico" - ou, como diria Mignolo (2002: 84-85) com esta "dependência epistêmica" - significa desestabilizar as assimetrias - oposições binárias "assimetrizadas", diria Luhmann - conceituais do tipo modernidade $\times$ atraso, desenvolvimento $\times$ subdesenvolvimento, positivamente moderno $\times$ negativamente moderno, civilizado $\times$ bárbaro $\times$ primitivo etc., que são, desde o desenvolvimento de comparações globais no século XIX, o cerne da "diferença colonial" (Mignolo, 2002) reproduzida pelo paradigma do "nacionalismo metodológico" que elege os países do Atlântico Norte como parâmetro de modernidade que orienta as comparações e portanto a construção e interpretação de diferenças sociais globais.

Meu argumento é que esta ruptura epistemológica sobre a sociedade mundial defendida por Walter Mignolo também se encontra presente na teoria de Niklas Luhmann. As análises sobre os efeitos e paradoxos da diferenciação funcional romperam, em grande medida, com o discurso hegemônico e teleológico sobre a modernidade, principalmente, como já afirmamos, na última fase do autor. Embora 
se possa dizer que Luhmann não observasse a operação de "diferenças coloniais" na constituição da diferenciação funcional europeia, não se pode concluir que ele faz uma equiparação entre Atlântico Norte e modernidade (Gonçalves, 2017). Sua teoria da diferenciação funcional é, nos anos 1990, radicalmente antirregionalista, a ponto de recusar a identificação de problemas de exclusão e de "corrupção sistêmica" como sendo apenas de certas regiões, tratando-os não como desvios da modernidade, mas sim como produtos genuínos e paradoxais de uma forma de diferenciação muito mais caótica e desintegrada do que coesa e integrada, como no discurso sociológico dominante de um Talcott Parsons.

A teoria da diferenciação funcional de Luhmann, como procurei demonstrar detaIhadamente alhures (Dutra, 2013; 2016), não constrói ontologias regionais, como podemos encontrar na tese de Marcelo Neves sobre o caráter periférico dos problemas de exclusão e corrupção sistêmica. Reduzi-la a mais uma "ideologia da sociedade (neo)colonial" não faz jus ao trabalho de Luhmann e oblitera o seu potencial ainda não desenvolvido na direção de uma "sociologia pós-colonial".

Para Mignolo, trata-se de operar desconstruções dos discursos hegemônicos e eurocêntricos sobre a modernidade, realizando uma observação crítica das operações cognitivas e práticas que constroem, num registro essencialista, identidades e casos nacionais baseados nas autocompreensões colonialistas dos países designados como centrais ou desenvolvidos. Tais desconstruções consistem basicamente em tornar visível a operação da "diferença colonial" (Mignolo, 2002) que, ao fim e ao cabo, termina sendo obliterada pela colonialidade embutida na construção dessas identidades essencialistas nacionais. O discurso da modernidade ocidental sobre si mesma - e sobre o seu "outro", o "Oriente", a "América Latina" - é, portanto, o principal objeto de desconstrução, tendo como estímulo histórico-empírico as experiências das regiões pós-coloniais com a modernidade.

Mignolo incorpora a tradição latino-americana dos estudos sobre dependência e as relações múltiplas entre centro e periferia para construir sua análise sobre o esquecimento da "diferença colonial" na filosofia e nas teorias sociais e políticas modernas. Para o semiólogo argentino, em esforço de ruptura com a tradição de pensamento ocidental em diversas disciplinas, que localizam a transição para a modernidade na virada do século XVIII para o século XIX, é preciso colocar os três séculos anteriores de relações coloniais no centro da análise sobre a modernidade. E como essas relações coloniais são constitutivas para a formação das identidades "geo-históricas" na Europa em processo de modernização, o próprio conceito de modernidade precisa vir sempre acoplado ao de colonialidade (Mignolo, 2017). 
Os estudos sobre dependência e as relações centro-periferia, cuja síntese teórica Mignolo localiza na obra de Immanuel Wallerstein,

[...] põem o colonialismo em tela, ainda que apenas como um elemento derivado, e não constitutivo, da modernidade, pois ainda não tornam visível a colonialidade, o outro (escuro?) lado da modernidade (Mignolo 2002: 60).

Sua tarefa é justamente a de trabalhar este "lado obscuro" a fim de superar a própria modernidade como condição para superar a colonialidade.

O esquecimento da "diferença colonial" - que não desaparece com o fim do colonialismo político-administrativo - só faz reforçar a estabilidade das identidades "geo-históricas" ocidentais construídas com base nesta mesma "diferença". Assim como nas discussões sobre o "Orientalismo" (Said, 2007) e no debate sobre a diferença mais abrangente entre o "Ocidente" e o "resto" (Hall, 1992), o que está em jogo aqui é a formação recíproca da imagem de si e da imagem do outro. A premissa teórica básica - partilhada por Said, Hall, Mignolo e muitos outros - é a de que a criação de identidades culturais ou "geo-históricas" depende de contrastes entre a própria identidade e uma alteridade construída como inferior. É justamente este contraste constitutivo que Mignolo chama de "diferença colonial", estabilizada como relação assimétrica entre povos moralmente inferiores e superiores, pela simples estabilização de qualquer um dos polos do contraste, mesmo que se esqueça que o outro polo da diferença, e logo a própria diferença, são constitutivos do único polo ressaltado: a identidade ocidental moderna.

O conceito de "diferença colonial" é o mais importante neste diálogo, pois permite observar, a partir da perspectiva pós-colonial, como as identidades "geo-históricas" do Atlântico Norte se constituem em uma "formação discursiva" (que em Luhmann equivale à dimensão semântica das estruturas sociais) assimétrica, estabilizada na diferença Ocidente $\times$ resto do mundo, que remonta às viagens de exploração e colonização comercial europeias dos séculos XV e XVI, mas que se desdobra na monopolização semântico-discursiva das ideias de desenvolvimento e modernidade por parte dos países ocidentais.

Para Mignolo, o esquecimento da "diferença colonial" produz e atualiza a invisibilização da continuidade de relações hierárquicas herdeiras da colonização. Isto ocorre de modo típico com o racismo em relação ao negro: um padrão de hierarquia que perpassa diferentes esferas sociais, da relação colonial entre senhor e escravo às formas modernas de discriminação e exclusão nas esferas da economia, 
da política, da justiça e da cultura. Para a teoria dos sistemas, a continuidade de relações hierárquicas como o racismo em relação ao negro precisa ser percebida em contexto de descontinuidade da forma primária de diferenciação da sociedade, que a passa a se dar como diferenciação de subsistemas de função - e não como diferença entre colonizador e colonizado - como na velha hierarquia unitária entre centro e periferia. Isto fica claro na análise das estruturas de inclusão e exclusão nos diferentes sistemas sociais.

A teoria dos sistemas enfatiza que a contingência e a possibilidade de não reprodução dessas hierarquias herdeiras da colonização são elementos constitutivos dos horizontes normativos e cognitivos da própria modernidade. Para Mignolo, esta possibilidade parece estar necessariamente anulada por estes horizontes modernos. O debate entre Luhmann e Mignolo - que proponho - pode ser entendido como um debate sobre a continuidade e a transformação das estruturas sociais, especialmente das estruturas hierárquicas herdeiras da colonização, na transição para a modernidade e no interior de seus horizontes contemporâneos.

No período colonial fundante do sistema-mundo moderno-colonial, a monopolização semântico-discursiva da Europa sobre as ideias de desenvolvimento e modernidade, e com isso sobre a própria construção da história universal, foi instituída pela criação do primeiro sistema universal de classificação e produção de identidades étnicas e posteriormente raciais, ajustado estruturalmente para legitimar as hierarquias da divisão social do trabalho do colonialismo comercial (Quijano \& Wallerstein, 1992: 550-552). Com o fim do colonialismo político-administrativo nos séculos XVIII e XIX, é justamente esta monopolização semântico-discursiva, reinstitucionalizada após a Segunda Guerra em uma ordem político-jurídica que promove a imposição de modelos institucionais e de ideias de modernidade e desenvolvimento dos países centrais para os periféricos, que vai permitir ao Ocidente recolonizar o resto do mundo, seja por meio de intervenções militares "humanitárias", ou de escandalizações morais seletivas e assimétricas em nome dos "direitos humanos". No trabalho de Mignolo (2002), esta monopolização semântico-discursiva é pensada em termos de uma "dependência epistêmica" (Mignolo, 2002: 84-85) generalizada que produz o esquecimento da "diferença colonial" e, com isso, da continuação da colonialidade como lado obscuro da modernidade.

Sua proposta é tematizar e tornar visível a operação desta "diferença colonial", tendo como pano de fundo não uma narrativa teórica universal, mas narrativas particulares a partir de cada contexto "geo-histórico" produzido na relação constitutiva entre modernidade e colonialidade. Programaticamente, esta proposta desdobra-se na ideia de "diversalidade", que é 
um projeto que se coloca como alternativa à universalidade e oferece a possibilidade de uma rede de confrontações planetárias com a globalização em nome da justiça, da equidade, dos direitos humanos e da diversalidade epistêmica (Mignolo, 2002: 90).

Assim como em outras teorias críticas da modernidade - e particularmente nas teorias críticas da dominação e da desigualdade -, o "pós-colonialismo", mesmo que não admita isto ao pretender fazer uma "crítica externa" da modernidade $\times$ colonialidade, baseia-se na episteme e em categorias modernas como equidade, direitos humanos e até mesmo na própria ideia de diversidade epistêmica. Querendo ou não, essas categorias remetem a padrões normativos que a própria modernidade forjou, e que servem de parâmetro não para críticas externas da vida moderna, mas para críticas internas e imanentes, que utilizam a semântica dos sistemas sociais modernos para criticar, desconstruir e tornar visíveis fraturas, incoerências, contradições, paradoxos, contingências e alternativas no desenvolvimento social e cultural.

Na próxima seção, analisaremos mais detidamente o problema da autologia na crítica pós-colonial, ou seja, o problema "iluminista sociológico" de refletir sobre as condições - e os limites - sociais de possibilidade da crítica social. Neste ponto, a teoria dos sistemas de Luhmann pode nos ajudar a corrigir o déficit de reflexividade autológica da crítica pós-colonial, identificando na superação, pelo sistema da sociedade, do caráter necessário e primário das diferenças de poder coloniais o eixo teórico central nesta tarefa de correção.

\section{As condições de possibilidade da crítica pós-colonial}

A questão das condições socioculturais de possibilidade da crítica pós-colonial nos remete diretamente à premissa epistemológica partilhada com a teoria dos sistemas, segundo a qual o conhecimento sobre o social - a observação do social, para Luhmann - é parte integrante do próprio objeto, ou seja, é sempre autoconhecimento e auto-observação do social possibilitados pelo social. No caso específico do pós-colonialismo, esta questão autológica está diretamente relacionada às condições de possibilidade de uma crítica de desigualdades sociais globais (Norte $\times$ Sul, centro $\times$ periferia etc.), que é, concretamente, o modo como a crítica pós-colonial se realiza, incluindo a do trabalho de Mignolo. E a questão autológica fundamental para uma teoria crítica das desigualdades, mesmo as de caráter "neocolonial", é a das condições de possibilidade da problematização sociológica - como autoproblematização social - das assimetrias entre pessoas, povos, nações, regiões etc. 
No trabalho de Mignolo (2002), a crítica pós-colonial se realiza como crítica do esquecimento da "diferença colonial" que produz e reproduz um poder de definição e classificação controlado pelo Ocidente, responsável pela criação e continuidade de uma identidade ocidental colocada como superior e uma alteridade não ocidental fixada como inferior. Sua concretização como crítica de desigualdades "neocoloniais" fica evidente quando a construção das identidades "geo-históricas" hierarquizadas é remetida a assimetrias étnico-raciais que se atualizam mesmo com o fim do colonialismo político-administrativo, na medida em que são institucionalizadas pela "colonialidade do poder" (Mignolo, 2002: 83). A crítica de Mignolo identifica na "diferença colonial" entre as identidades "neocoloniais" (do Atlântico Norte) e "neocolonizadas" (no nosso caso, a América Latina) a fonte unificada de todas as outras formas de dependência e hierarquia, constituindo a "essência pura da colonialidade do poder" (Mignolo, 2002: 84-85).

Neste ponto, também podemos identificar o já apontado (Ruggero, 2009) déficit de reflexividade autológica da crítica pós-colonial. Ao eleger uma fonte única de produção e reprodução das desigualdades herdeiras da colonização - a "colonialidade" -, ela acaba pressupondo um primado da "diferença colonial" sobre a constituição e o funcionamento de todas as instituições e sistemas da sociedade global. O déficit de reflexividade autológica reside precisamente neste pressuposto, pois, na vigência do primado da "diferença colonial", a crítica da "colonialidade do poder" não seria possível enquanto saber do social sobre o social. O "Iugar de enunciação" da crítica pós-colonial não se sustenta enquanto "exterioridade" (Mignolo, 2002: 62): ou ele está internamente implicado na própria "diferença coIonial", o que representaria uma impossibilidade disfarçada com a busca de um "lugar híbrido de enunciação", ou ele está internamente implicado em formas de sociabilidade que transcendem a "diferença colonial". Meu argumento é que uma reflexão autológica da crítica pós-colonial nos conduz a esta segunda alternativa: a de uma teoria pós-colonial sociologicamente informada de que sua própria existência é produto de uma sociedade global que transcende a "diferença colonial" e a "colonialidade do poder".

Em termos sociologicamente mais precisos, transcender a "diferença colonial" e a "colonialidade do poder" significa a constituição de um patamar global de complexidade social, no qual se torna impraticável uma mesma hierarquia colonial ou neocolonial estruturar o funcionamento de desigualdades em todas as esferas e dimensões da vida social. Em outros termos: significa que as assimetrias neocoloniais - cuja emergência e estabilização o próprio Luhmann identificou como constitutivas para as identidades nacionais europeias no século XIX e XX - não poderiam jamais ser desestabilizadas na evolução dos distintos sistemas funcionais da socie- 
2. Mas - como sugiro -, se partimos do primado da diferenciação funcional, qual seria o estatuto teórico das hierarquias coloniais ou neocoloniais que inegavelmente persistem e se atualizam na sociedade global, ainda que esta não possa ser definida como primariamente neocolonial? Para Santiago Ruggero (2009), no caso da América Latina, a hipótese de um primado da "diferença colonial" só faz sentido no período de conquista e colonização, pois a forma primária de diferenciação da sociedade era entre centro e periferia: "Se dieron numerosos modos de contro de comunicaciones de la periferia por parte del centro, en el caso de la periferia Latinoamérica y el centro Europa, tales como dominio territorial, control militar, control de puertos, exterminios, implantación de roles sociales, mestizaje, evangelización, y la implantación de medios de comunicación lenguajes del centro en el primer caso, y la escritura occidental en el segundo caso" (Ruggero 2009: 7). Em consonância com a crítica pós-colonial este primado da diferença centro $x$ periferia entre os séculos XV e XIX tem na constituição dade global. Ora, mas é justamente esta desestabilização que podemos identificar em situação de quase coexistência com a semântica neocolonial.

Em diferentes sistemas funcionais, mas sobretudo na própria política de importantes Estados nacionais, o século XX dá testemunho do surgimento não só de críticas sociais e políticas do neocolonialismo, como também da efetiva constituição de estruturas e processos anticoloniais, desenvolvimentistas, anti-imperialistas, que lograram alterar significativamente, em diferentes momentos, as estruturas globais de poder. Ao fim e ao cabo, a reflexividade autológica que cobramos da crítica pós-colonial tem o objetivo de situar sua própria semântica crítica no interior de estruturas e processos anticoloniais, cuja existência pressupõe uma sociedade global cuja diferença primária não é uma "diferença colonial" unitária e vigente em todas as esferas sociais, mas sim uma sociedade formada por um conjunto diferenciado de esferas nas quais diferentes estruturas neocoloniais ou anticoloniais se desenvolvem de modo não necessariamente relacionado. O problema teórico fundamental é, portanto, se as diferenças regionais - sejam elas neocoloniais ou não - devem ser explicadas a partir do primado da "diferença colonial" ou do primado da diferenciação funcional².

O debate entre transformação e continuidade das estruturas sociais herdeiras da colonização se evidencia também no tema da transição do colonialismo político-administrativo para os Estados nacionais, enquanto forma especificamente moderna de controle político e jurídico de territórios. Da perspectiva da teoria dos sistemas - e em oposição ao que sugere a crítica pós-colonial -, o primado da "diferença colonial" não se reproduz com o fim do colonialismo político-administrativo. Isto porque a formação de Estados nacionais, ainda que periféricos e dependentes, não é um processo isolado, mas parte da constituição de sistemas funcionais globais (Werron, 2007), o que resulta na fragmentação das relações entre centro e periferia. Ao invés de uma "diferença colonial" unitária, estruturada em torno de um único centro capaz de controlar toda(s) a(s) periferia(s), temos um conjunto diferenciado de relações centro $\times$ periferia, que não se deixa subsumir a uma única diferença. Neste novo contexto, a "colonialidade" continua existindo, mas agora não mais como forma primária de estruturação das sociabilidades globais. Ela

\footnotetext{
funciona como actualización de estructuras de centro y periferia como forma de diferenciación dentro de la forma primaria de diferenciación por funciones. Es decir, que en el sistema social global funcionalmente diferenciado, si bien no posee un centro especifico, posee tantos centros como sistemas con forma centro y periferia dentro de su diferenciación funcional haya. No siendo la división del trabajo la única diferenciación entre centro y periferia (Ruggero, 2009: 9).
} 
Esta diferenciação funcional das relações centro $\times$ periferia tem pelo menos três importantes implicações para o estatuto das hierarquias neocoloniais entre Norte $\times$ Sul, centro $\times$ periferia etc.

i. A condição periférica ou neocolonial não é uma posição estrutural unitária, definida territorialmente como identidade "geo-histórica". Nem todos os sistemas funcionais em um país econômica, científica e politicamente periférico seguem a mesma dinâmica de reprodução da diferença centro $\times$ periferia. $O$ vigor da modernidade religiosa no Brasil, por exemplo, desautoriza o uso da categoria de periferia para esta esfera específica, indicando que o centro do sistema funcional da religião não converge com os centros da modernidade econômica ou científica (Dutra, 2016b). As diferenças regionais devem ser pensadas como relativas a determinados sistemas funcionais de referência e não como absolutas e unificadas em torno de um eixo centro $\times$ periferia vigente em todos os sistemas funcionais.

ii. A condição periférica ou neocolonial é produto de diferenciações centro $\times$ periferia, que podem acontecer tanto em países centrais como nos periféricos, podendo-se falar da internalização de "centros" nos países periféricos e da internalização de "periferias" nos países centrais. Em termos especificamente luhmannianos: a "reentrada" (re-entry) das diferenças centro $\times$ periferia acontece tanto no centro como na periferia. Na Europa, segundo a própria análise de Mignolo, houve, a partir do século XVIII, uma "periferização" dos centros econômicos, culturais e políticos formados na península ibérica com a conquista e colonização dos séculos XV e XVI. Mignolo (2002: 62) identifica esta "cópia" da diferença centro x periferia no centro com a metáfora da formação de um "Terceiro Mundo dentro do Primeiro Mundo". Na periferia, a "reentrada" acontece, por exemplo, com a formação de centros acadêmicos cujas condições e os estímulos para o trabalho levam à importação de questões, métodos e teorias que, ao mesmo tempo em que constituem e reproduzem o "colonialismo mental" na periferia, também conferem a seus agentes um status de "centro na periferia".

iii. Neste contexto - como Luhmann (1995b) mesmo percebeu -, a "colonialidade" também pode assumir a forma de "autodescrições assimetrizantes", de semânticas neocoloniais. Ao contrário de Ruggero (2009: 9), não identifico relação de exclusão mútua entre esta forma semântica da "colonialidade" e a tese de que ela assume formas plu- da colonialidade como "meio de comunicação simbolicamente generalizado" e na formação de identidades raciais enquanto "mecanismo simbiótico" os fundamentos de sua produção e reprodução nas práticas cotidianas. Isso significa que as principais comunicações da sociedade são diretamente estruturadas por desigualdades colonial-raciais concretas, por uma estrutura de desigualdade unitária vigente em todas as esferas sociais. 
rais e diferenciadas, de acordo com a lógica de cada sistema funcional. Em verdade, a semântica é constitutiva das estruturas sociais (Stäheli, 2009) e isto acontece também com a "colonialidade". Formas específicas de auto-observação e autodescrição, como aquelas encontradas por Fabrício Neves (2009) na biociência praticada no Brasil, atribuem status de "periféricas" às práticas sociais realizadas em determinados territórios. Deve-se ressaltar que esta atribuição de status é decisiva para a própria constituição e reprodução das relações entre centro e periferia. Como os pós-coloniais sempre ressaltam, a "colonialidade" é invariavelmente constituída pelas semânticas que orientam a interpretação do mundo social. Para Mignolo, estas semânticas promovem o esquecimento e a reprodução invisível da "diferença colonial". A ênfase conferida às "formações discursivas" por Mignolo e outros pós-coloniais deve, no entanto, ser aqui complementada pela ênfase nas práticas reais de classificação e interpretação, pois só assim é possível observar a contingência das semânticas neocoloniais.

\section{Considerações finais: \\ algumas correções internas na teoria sistêmica para uma sociologia pós-colonial}

Nestas considerações finais, gostaria de esboçar os traços básicos de uma teoria sistêmica da sociedade mundial submetida a um processo de descolonização. Se até aqui enfatizamos o que a crítica pós-colonial deve corrigir a partir de um esforço de reflexividade autológica que resulta em questionar o primado da "diferença colonial" como pressuposto de sua descrição das diferenças sociais globais, agora pretendo indicar o que precisa ser corrigido na teoria da sociedade mundial de Luhmann para que ela não fique cega à "diferença colonial" e assim seja capaz de inspirar uma "sociologia pós-colonial".

Quando aplicada fora do Atlântico Norte, ficam mais evidentes as dificuldades em escapar de uma leitura "neocolonial" (Gonçalves, 2017) da teoria luhmanniana da sociedade mundial funcionalmente diferenciada. Exemplo consolidado deste tipo de leitura é o trabalho de Marcelo Neves (1992; 2012) sobre os problemas de (des) diferenciação do direito no Brasil, do qual resulta a tese geral da ausência de diferenciação funcional na América Latina. Segundo Neves, no Brasil e na América Latina - diferentemente do que ocorreria nos países centrais da Europa e da América do Norte -, o primado da diferenciação funcional seria solapado pela "corrupção sistêmica estrutural" típica da "modernidade negativa ou periferia". 
A ideia de que na Europa e nos Estados Unidos a inclusão e a exclusão nos sistemas funcionais são efetivamente estruturadas por mecanismos universalistas e pautadas exclusivamente por normas constitucionais ignora a realidade de desigualdades sociais estruturadas segundo mecanismos particularistas. Para superar este problema, é necessária uma simultânea correção teórica sobre a tese luhmanniana do primado da diferenciação funcional.

Como tentei demonstrar alhures (2013; 2016a), a diferenciação funcional constitui o pano de fundo global para a observação de regiões (ou outras unidades sociais/ socioespaciais, como países, classes, etnias etc.) como desviantes em relação a outras, de acordo com o padrão de autonomia sistêmica e inclusão tomados como referência comparativa. Ocorre, porém, que a escolha da referência comparativa está definida ontologicamente como sendo a Europa e os Estados Unidos. Ainda que haja permanentes desigualdades na capacidade de estabelecer - e estabelecer-se como - a referência comparativa, a teoria de Luhmann, apesar de seus componentes eurocêntricos, prevê uma pluralização e não uma insuperável concentração territorial das unidades tomadas como critério de sucesso na realização das funções sociais diferenciadas na modernidade.

As críticas "pós-coloniais" - especialmente a de Mignolo com sua associação à teoria do sistema-mundo e com seu foco na dimensão cognitiva da colonialidade eurocêntrica - desejam a ampliação do leque de modelos normativos sobre a vida política, econômica e jurídica de povos, nações e países da "periferia", e com isso a pluralização das referências comparativas globais em todas as esferas da sociedade. O interesse de Mignolo pela filosofia e ciência social produzidas na África e na Ásia testemunham exatamente esta pluralização no interior do sistema científico global, no qual o intelectual argentino tem ampla liberdade de circulação, fala e audiência. Sua pretensão intelectual - e também política - pode ser atendida com as ferramentas da teoria da sociedade de Luhmann, na qual a sociedade mundial é composta por uma variedade de referências comparativas (Schmidt, 2012), entre as quais estão os Estados nacionais, mas não apenas eles. E com a vantagem de se trabalhar de modo mais consequente com a questão da autologia: refletir sobre a condição social de possibilidade da própria observação crítica "pós-colonial"3.

No entanto, a construção desta sociologia sistêmica pós-colonial exige uma correção fundamental na narrativa luhmanniana sobre a gênese da sociedade funcionalmente diferenciada: é preciso rever a tese da transição à sociedade funcionalmente diferenciada a fim de escapar da narrativa da singularidade ocidental (Chakrabarty, 2000: 7), segundo a qual a modernidade emergiu primeiro na Europa e depois se expandiu para outros lugares.
3. A leitura da teoria de Luhmann realiza por Aldo Mascareño (2003; 2012) propõe uma alternativa à caracterização da modernidade na América Latina pelo critério do "déficit" de diferenciação e inclusão. Sua inovação é a diferença entre as variantes policêntrica e concêntrica da diferenciação funcional. Enquanto a variante policêntrica seria vigente na Europa e na América do Norte, a variante concêntrica estruturada pelo centralismo estatal caracterizaria a modernidade latino-americana. No entanto - a meu ver -, esta inovação, ao tomar o Atlântico Norte como o caso de realização das potencialidades de autonomia e descentralização sistêmico-funcional com sua estrutura policêntrica, acaba reproduzindo o modelo "neocolonial" de comparação, no qual o Atlântico Norte é o parâmetro natural das realizações sociais e culturais da modernidade. Como se pode notar, a análise de Mascareño atribui o caráter concêntrico da diferenciação funcional na América Latina ao papel centralizador do Estado, o qual seria responsável por induzir processos de (des)diferenciação entre a política e outros sistemas 
funcionais como o direito e a economia. Assim como a análise de Marcelo Neves, a de Mascareño também parece padecer de alguns problemas empíricos, embora não dos mesmos:

i. Generalizar o papel do Estado, como se seu protagonismo na construção de ordens sociais concêntricas fosse o mesmo em todo o continente latino-americano. Esta narrativa, de resto caudatária do discurso liberalconservador que atribui sempre ao Estado a fonte dos problemas e à sua redução a fonte de soluções, não leva em conta as enormes diferenças não só entre as capacidades estatais dos países (entre Brasil e Bolívia, por exemplo), como àquelas internas aos próprios países. Como vimos acima, a reconstrução histórico-sociológica (Hahn, 1993) evidencia que não há, pelo menos como relação causal necessária, um jogo de soma zero entre construção e fortalecimento dos papéis do Estado e diferenciação de outros sistemas funcionais. Ao levar em conta este dado histórico, o papel dos Estados nacionais na América Latina, sobretudo nos períodos de maior fortalecimento de
O maior desafio para a teoria da sociedade mundial é o de problematizar a história da modernidade, substituindo a narrativa única de uma diferenciação funcional desenvolvida no interior da Europa e depois apenas expandida para o resto do mundo por narrativas plurais sobre a experiência de cada contexto "geo-histórico" com o desenvolvimento "entrelaçado" (Randeria, 2000) e "múltiplo" (Eisenstadt, 2000) de sistemas funcionais globais (Grizelj \& Kirschstein, 2014: 12), mesmo que estes sistemas tenham seu centro na Europa. O componente mais "eurocêntrico" da teoria de Luhmann - ou seja, aquele que menos reflete sua preocupação tardia em conduzir sua própria teoria a um giro reflexivo sobre as diferenças regionais é sua descrição da transição para a sociedade funcionalmente diferenciada como fenômeno interno à Europa até o século XVIII, para somente depois, já nos séculos XIX e XX, globalizar-se e assumir conexões e referências fora da Europa.

Possivelmente - como defende a crítica pós-colonial - a correção dessa narrativa inclui reavaliar o papel da diferença centro $\times$ periferia na narrativa da transição. Para Luhmann, a transição, na Europa, deu-se a partir da diferenciação estratificada entre "nobres" e "povo comum", havendo um silenciamento das diferenças coloniais entre centro e periferia neste processo. Não se trata de negar a centralidade da Europa no processo de surgimento da modernidade, mas sim de observá-la a partir da própria diferença centro $\times$ periferia, o que se configura - a meu ver como resultado de um diálogo crítico e produtivo entre a teoria dos sistemas e o pós-colonialismo. Como ressalta Domingues (2008: 125-126), não é necessário negar a - inegável - centralidade da Europa na formação inicial da modernidade para ressaltar o papel constitutivo que os contatos e entrelaçamentos com outras regiões do planeta tiveram neste processo.

Neste quadro teórico, a construção de desigualdades regionais do tipo centro × periferia não é vista como eixo estrutural necessário da modernidade global - o que chamo de "primado da diferença colonial" -, mas sim como processo contingente e multidimensional.

Neste debate com Mignolo, podemos corrigir a teoria dos sistemas e libertá-la de seu viés eurocêntrico, mas sem a pretensão de fazer uma descrição externa da sociedade global, a partir de sua exterioridade periférica, o que não existe enquanto "lugar de enunciação", pois as periferias da modernidade foram internalizadas e fragmentadas pelo primado da diferenciação funcional. As possíveis contribuições de uma sociologia sistêmica pós-colonial - críticas ou não - estão dentro do sistema da sociedade global. 
Referências

ARALDI, Claudio; CORSI, Giancarlo; ESPOSITO, Elena. Glossar zu Niklas Luhmanns theorie sozialer systeme. Frankfurt a. M.: Suhrkamp, 1997.

BOATCĂ, Manuela; COSTA, Sérgio. Postkoloniale Soziologie: ein Programm. In: REUTER, Julia; VILLA, Paula-Irene (Orgs.). Postkoloniale Soziologie. Empirische Befunde, theoretische Anschlüsse, politische Intervention, p. 69-91. Bielefeld: Transcript, 2010.

BOMMES, Michael. Zur Bildung von Verteilungsordnungen in der funktional differenzierten Gesellschaft. Erläutert am Beispiel, ethnischer Ungleichheit' von Arbeitsmigranten; In: SCHWINN, Thomas (Org.). Differenzierung und Soziale Ungleichheit. Die zwei Soziologien und ihre Verknüpfung. Frankfurt a. M: Humanities Online, 2004.

BRINGEL, Breno; DOMINGUES, José Maurício. Teoria social, extroversão e autonomia: impasses e horizontes da sociologia (semi)periférica contemporânea. Cad. CRH, v. 28, n. 73, p. 59-76, 2015.

BUTLER, Judith. Contingent foundations: feminisms and the question of 'postmodernism'. In: BUTLER, Judith; WALLACH SCOT, Joan (Orgs.). Feminists theorize the political, p. 3-21. New York: Routledge, 1992.

CHAKRABARTY, Dispesh. Provicializing Europe: postcolonial thought and historical difference. Princeton (NJ): University of Princeton, 2000.

COSTA, Sérgio. Desprovincializando a sociologia - a contribuição pós-colonial. Revista Brasileira de Ciências Sociais, v. 21, n. 60, p. 117-134, 2006.

DOMINGUES, José Maurício. Latin America and contemporary modernity. A sociological interpretation. New York: Routledge, 2008.

DUTRA, Roberto. Diferenciação funcional e a sociologia da modernidade brasileira. Política e Sociedade, v. 15, n. 34, p. 77-109, 2016a.

. A universalidade da condição secular. Religião e sociedade, v. 36, n. 1, p. 151-174, 2016b.

_ . O problema da desigualdade social na teoria da sociedade de Niklas Luhmann. Cad. CRH, v. 27, n. 72, p. 547-561, 2014.

. Funktionale Differenzierung, soziale Ungleichheit und Exklusion. Konstanz: UVK, 2013 suas capacidades como no nacionaldesenvolvimentismo do século $X X$ revela-se muito parecido àquele desempenhado ontem e hoje na Europa e até mesmo nos Estados Unidos;

ii. Reproduzir caricaturas regionais - o que chamei alhures (Dutra, 2016a) de "ontologização da região" - é outo problema empírico decorrente da identificação de padrões de diferenciação funcional com países ou regiões inteiras, como se a semântica territorial (Norte $x$ Sul, por exemplo) engendrasse uma estrutura hierárquica entre centro e periferia unitária e totalizante. Os processos de periferização e centralização de práticas sociais às vezes obedecem a fronteiras territoriais, nacionais ou regionais, mas não o fazem sempre e nunca de modo necessário. Sua localização territorial é contingente. Nos países periféricos há, por exemplo, processos de centralização na ciência (Neves, 2009), assim como há processos de periferização em países centrais. Ou seja, para construir uma teoria sistêmica pós-colonial da modernidade na América Latina é preciso não substituir o nacionalismo 
pelo "regionalismo metodológico", rompendo efetivamente o "obstáculo epistemológico" regionalista caricatural de pressupor um padrão especificamente "latino-americano" de modernidade, seja ela concêntrica, negativa, ou periférica, pois estes atributos não estão ontologicamente relacionados a qualquer região.
ECKSTEIN, Lars; REINFANDT, Christoph. Luhmann in the Contact Zone: Zur Theorie einer transkulturellen Moderne. In: GRIZELJ, Mario; KIRSCHSTEIN, Daniela (Orgs.). Riskante Kontakte: Postkoloniale Theorien und Systemtheorie?, p. 107-124. Berlin: Kadmos, 2014.

EISENSTADT, Shmuel. N. Die Vielfalt der Moderne. Weilerswist: Velbrück Wissenschaft, 2000.

FERES JÚNIOR, João. Spanish America como o outro da América. Lua Nova, v. 26, n. 62, p. 69-91, 2004.

GARCIA DA COSTA, Everton. G.; RODRIGUES, Leo Peixoto. Teoria dos sistemas sociais, teoria do discurso e pós-fundacionismo: um diálogo possível. In: RODRIGUES, L. P.; NEVES, F. M. (Orgs.). Niklas Luhmann. Sistemas sociais: ensaios teóricos, p. 145-167. Porto Alegre: Editora Pontifícia Universidade Católica do Rio Grande do Sul, 2017.

GONÇALVES, Guilherme Leite. Functional differentiation as ideology of the (neo) colonial society. Thesis Eleven, v. 143, n. 1, p. 70-81, 2017.

. Pós-colonialismo e teoria dos sistemas: notas para uma agenda de pesquisa sobre o direito. In: DUTRA, Roberto; BACHUR, João Paulo (Orgs.). Dossiê Niklas Luhmann, p. 249-278. Belo Horizonte: Editora UFMG, 2013.

GRIZELJ, Mario; KIRSCHSTEIN, Daniela (Orgs.). Riskante Kontakte: Postkoloniale Theorien und Systemtheorie? Berlin: Kadmos, 2014.

HALL, Stuart. The West and the Rest: Discourse and Power. In: HALL, Stuart; GIEBEN, Bram (Orgs.). Formations of modernity, p. 275-320. Cambridge (UK): Polity Press; Open University, 1992.

HAHN, Alois. Identität und Nation in Europa. Berliner Journal für Soziologie, v. 3, p. 193-203, 1993

HEINTZ, Bettina; WERRON, Tobias. Wie ist Globalisierung möglich? Zur Entstehung globaler Vergleichshorizonte am Beispiel von Wissenschaft und Sport. Kölner Zeitschrift für Soziologie und Sozialpsychologie, v. 63, p. 359-394, 2011.

HOLMES, Pablo. Verfassungsevolution in der Weltgesellschaft. Differenzierungsprobleme des Rechts und der Politik im Zeitalter der Global Governance. Baden-Baden: Nomos, 2013.

LUHMANN, Niklas. Zum Begriff der sozialen Klasse. In: LUHMANN, Niklas. Ideenevolution. Beiträge zur Wissenssoziologie, p.72-131. Frankfurt a. M.: Suhrkamp, 2008. 
—. Die Politik der Gesellschaft. KIESERLING, André (Org.). Frankfurt a. M: Suhrkamp, 2002.

—. Die Gesellschaft der Gesellschaft. v. 1 e 2. Frankfurt a. M: Suhrkamp, 1997.

—. Kausalität im Süden. Soziale Systeme, n. 1, 1995a.

—. Jenseits von Barbarei. In: LUHMANN, Niklas. Gesellschaftsstruktur und Semantik 4 , p. 138-150. Frankfurt a. M.: Suhrkamp, 1995b.

- Symbiotische Mechanismen. In: LUHMANN, Niklas. Soziologische Aufklärung 3, p. 228-244. Opladen: Westdeutscher Verlag, 1981.

MASCAREÑO, Aldo. Die Moderne Lateinamerikas. Weltgesellschft, Region und funktionale Differenzierung. Bielefeld, transcript, 2012.

— Teoría de sistemas de América Latina. Conceptos fundamentales para la descripción de una diferenciación funcional concêntrica. Revista Persona y Sociedad, v. 17, n. 2, p. 9-26, 2003.

MIGLIEVICH-RIBEIRO, Adélia. Por uma razão decolonial: desafios ético-políticos-epistemológicos à cosmovisão moderna. Civitas - Revista de Ciências Sociais, v. 14, n. 1, p. 66-80, 2014.

MIGNOLO, Walter. Colonialidade: o lado mais escuro da modernidade. Revista Brasileira de Ciências Sociais, v. 32, n. 94, p. 1-18, 2017.

. The geopolitics of knowledge and the colonial difference. The South Atlantic Quarterly, v. 101, n. 1, p. 57-96, 2002.

NASSEHI, Armin. Kultur im System: einige programmatische Bemerkungen zu einer systemtheoretisch informierten Kultursoziologie. In: WOHLRAB-SAHR, Monika (Org.). Kultursoziologie: Paradigmen-Methoden-Fragstellungen, p. 375-395. Wiesbaden: VS Verlag, 2010.

NEVES, Fabrício M. A contextualização da verdade ou como a ciência torna-se periférica. Civitas - Revista de Ciências Sociais, v. 14, n. 3, p. 556-574, 2014.

—. A diferenciação centro-periferia como estratégia teórica básica para observar a produção científica. Rev. Sociol. Polit., v. 17, n. 34, p. 241-252, 2009.

NEVES, Marcelo. Komplexitätssteigerung unter mangelhafter funktionaler Differenzierung. Das paradox der sozialen Entwicklung Lateinamerikas. In: BIRLE, Peter et alii (Orgs.). Durch Luhmanns Brille. Herausforderungen an Politik und an Recht in Latein Amerika und in der Weltgesellschaft. Wiesbaden: Springer; VS Verlag, 2012. 
— Die Staaten im Zentrum und die Saaten an der Peripherie. Einige probleme mit Niklas Luhmanns Auffassung von den Staaten der Weltgesellschaft. Soziale Systeme, v. 12, p. 247-273, 2006.

_ . Verfassung und Positivität des Rechts in der peripheren Moderne: eine theoretische Betrachtung und eine Interpretation des Falls Brasiliens. Berlin: Duncker und Humblot, 1992.

PARSONS, Talcott. The system of modern societies. Englewood Cliffs (NJ): Prentice-Hall Inc., 1971.

QUIJANO, Aníbal. Colonialidad del poder, cultura y conocimiento en América Latina. Anuario Mariateguiano, v. 101, n. 1, p. 113-122, 1997.

QUIJANO, Aníbal; WALLERSTEIN, Immanuel. Americanity as a concept, or the Americas in the modern world-system. International Social Science Journal, v. 44, n. 4, p. 549-557, 1992.

DE GIORGI, Raffaele. Periferias da modernidade. Revista Direito Makenzie, v. 11, n. 2, p. 39-47, 2017.

RAMOS, Alberto Guerreiro. A modernização em nova perspectiva: em busca do modelo da possibilidade. Revista de Administração Pública, v. 17, n. 1, p. 6-51, 1983.

RANDERIA, Shalini. Jenseits von Soziologie und soziokultureller Anthropologie: Zur Ortbestimmung der nichtwestlichen Welt in einer zukünftigen Sozialtheorie. In: BECK, Ulrich; KIESERLING, Andre (Orgs.). Ortsbestimmung der Soziologie: Wie die kommenden Generation Gesellschaftswissenschaften betreiben will, p. 41-50. Baden-Baden, Nomos, 2000.

RUGGERO, Santiago. América Latina y la colonialidad. Un abordaje sistémico de las teorías poscoloniales para una teoría pós-colonial. XXVII Congreso de la Asociación Latinoamericana de Sociología. VIII Jornadas de Sociología de la Universidad de Buenos Aires. Asociación Latinoamericana de Sociología, Buenos Aires, 2009. Disponível em: <http://cdsa.aacademica.org/000-062/1211.pdf>. Acessado em: 20 Mar. 2018.

SAID, Edward. Orientalismo. O Oriente como invenção do Ocidente. São Paulo: Companhia das Letras, 2007.

SCHMIDT, Volker. Conceptualizing global modernity. A tentative sketch. Working paper series, National University of Singapore, 2012. 
SOUZA, Jessé. Niklas Luhmann, Marcelo Neves e o "culturalismo cibernético" da moderna teoria sistêmica. In: DUTRA, Roberto; BACHUR, João Paulo (Orgs.). Dossiê Niklas Luhmann, p. 149-182. Belo Horizonte: Editora UFMG, 2013.

Jenseits von Zentrum und Peripherie. Über die symbolische Dimension des Kapitalismus. Berliner Journal für Soziologie, v. 21, n. 1, p. 23-38, 2011.

STÄHELI, Urs. Die Konstruktion des Finanzpublikums: eine genealogische Analyse. In: STICHWEH, Rudolf; WINDOLF, Paul (Orgs.). Inklusion und Exklusion: Analysen zur Sozialstruktur und sozialen Ungleichheit, p. 259-272. Wiesbaden: VS Verlag, 2009.

TAVOLARO, Sérgio B. F. A tese da singularidade brasileira revisitada: desafios teóricos contemporâneos. Dados, v. 57, n. 3, p. 633-673, 2014.

UNGER, Roberto Mangabeira. O que a esquerda deve propor. Rio de Janeiro: Civilização Brasileira, 2008.

- False necessity: anti-necessitarian social theory in the service of radical democracy. New York: Verso, 2004.

WEIß, Anja. Soziologie globaler Ungleichheiten. Frankfurt a. M.: Suhrkamp, 2017.

. Raumrelationen als zentraler Aspekt weltweiter Ungleichheiten. Mittelweg, v. 2, p. 76-91, 2002.

WERRON, Tobias. Publika. Zur Globalisierungsdynbamik von Funktionssystemen. Soziale Systeme, v. 13, p. 386-388, 2007.

(c) (1) $(9$ 
